\title{
The Quaternary glaciation of Shesan Mountain in Taiwan and glacial classification in monsoon areas
}

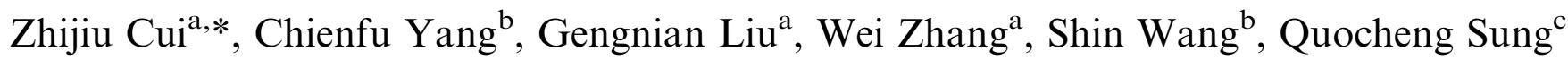 \\ ${ }^{a}$ Department of Geography, Peking University, Beijing 100871, China \\ ${ }^{\mathrm{b}}$ Department of Geography, National Taiwan University, Taipei, Taiwan, China \\ ${ }^{\mathrm{c}}$ Department of Earth Science, National Chen-Kung University, Tainan, Taiwan, China
}

\begin{abstract}
Cirques, glacial polished bedrock and moraines provide evidence for three stages of the last glaciation in Shesan Mountain in Taiwan. These are the Shangzhuang $(44.25 \pm 3.72 \mathrm{ka})$, the Shuiyuan $(18.62 \pm 1.52 \mathrm{ka})$, and the Xueshan $(10.68 \pm 0.84 \mathrm{ka})$ glaciations. The glaciation became progressively less extensive with time. The monsoon development during the last glacial, especially marine isotope stages 2 and 4, is discussed in relation to glaciation in Taiwan. (C) 2002 Published by Elsevier Science Ltd.
\end{abstract}

\section{Introduction}

There has been much contention over whether there is geologic evidence for former glaciations in the high mountains of Taiwan. Although the Japanese geographer Kano (1932, 1934a-e) reported many glacial remains on the high mountains of Taiwan, Taiwanese geologists challenged his findings (Zhang Xinpu, 1960; $\mathrm{Xu}$ Tieliang, 1990). They emphasized the need for further research in the valleys of Nanhutashan Mountain. Unfortunately, there is little detailed study on the formative environment during the last glaciation with the exception of Yang et al. (1998) and Cui et al. (2000 a, b).

There is direct and indirect evidence that supports the former existence of Quaternary glaciers in the high mountain areas. The direct evidence focuses on identifying the cirques and striations on the surface of bedrock and on clasts within moraine-like landforms. This is the best evidence for former glaciation, while the analysis of sediments and dating can clarify glacial genesis. This study will examine the cirques of the accessible main peak of Shesan Mountain. The indirect evidence uses the laws governing variations of air temperature and precipitation with altitude in order to conclude and calculate the ELA in modern times and during the last glaciation. Our study shows direct evidence in the form of striations on the polished surface of rocks and cirque

*Corresponding author.

E-mail address: czj_pku@ccermail.net (Z. Cui). threshold located on the floors of every cirque of Shesan Mountain during the last glaciation.

Based on field studies, Kano (1932, 1934a-e) and Tanaka and Kano (1934) argued that glacial remains exist in the high mountain zones at more than $3300 \mathrm{~m}$ a.s.l. They estimated that there are about 80 cirques on the high mountains of Taiwan including 35 cirques in the Shesan Mountain district at altitudes above $3500 \mathrm{~m}$ a.s.l. (Lin Chaoxian, 1957) and 12 cirques in Nanhutashan Mountain at altitudes above $3300 \mathrm{~m}$ a.s.l. The altitude of these cirques are related to snow line elevation. Kano showed that the former snow line elevations on Shesan Mountain and Nanhutashan mountain during the last glaciation were at 3500 and $3400 \mathrm{~m}$ a.s.l., respectively.

Ceng Chaoxian (1993) supported the view that Quaternary glaciers existed on the high mountains of Taiwan. Ono and Naruse (1997) calculated the equilibrium line altitude (ELA) distribution around Taiwan, but their ELA data basically depended on the reports of Kano's studies, so they were not quite sure of the reliability of their primary data.

\section{Geomorphic evidence}

The glacial landforms and their distribution were studied in detail in the field on Shesan Mountain where Kano reported the glacial features. Similar studies also have begun at Nanhutashan (Bose, 1997). Our field 
investigation was undertaken in the summers of 1998 and 1999. Three types of evidence for Quaternary glaciation were found: (i) glacial polished surfaces in the head region of No. 2 Cirque-U-Shaped valley; (ii) glacially polished surfaces and striations in the middle of No. 1 Cirque-U-Shaped valley; and (iii) moraines in the upper and lower parts of No. 1 Cirque-U-Shaped valley (Fig. 1).

\subsection{Polished surfaces and striations}

A large polished surface was discovered in the southern side of the middle of No. 1 valley that contains a cirque and is U-shaped. The exposed surface is about $10 \mathrm{~m}^{2}$, and the total area appears to be larger than $300 \mathrm{~m}^{2}$. The surface is located at an altitude of $3400 \mathrm{~m}$ a.s.1. in the "Black Forest" named after the forest of Taiwan cedar around this locality (Figs. 2 and 3). It probably represents the glacier threshold.

An exposed area of bare polished bedrock along the climbing path is about $5-6 \mathrm{~m}^{2}$, corresponding to only a small part of the whole glacier threshold. This glacier threshold extends $70 \mathrm{~m}$ on the southern slope near this path. Striations are abundant on the polished surface. They are commonly $20 \mathrm{~cm}$ long, but some reach $50 \mathrm{~cm}$ in length. The width is $0.2-0.5 \mathrm{~cm}$. The depth is $0.2-0.3 \mathrm{~cm}$. On the northern side of the path, well-marked grooves are present on the polished surface beneath a thick sod cover. Striated glacial boulders are also present on the path.

\subsection{Depression of ice erosion and glacier threshold}

No. 2 valley is a broad $\mathrm{u}$-shaped valley containing a cirque, and is located in the northwest flank of Shesan Mountain (Fig. 1). The combination of cirques and glacier thresholds at the source (Figs. 4 and 5) suggests a glacial origin. The excavation and transportation in the lower part of glacier caused a cirque to form, beyond which the glacier threshold is convex.

The floor of No. 2 valley is $7 \mathrm{~m}$ lower than the top of glacier threshold. However, the original cirque floor is covered by lake sediment and slope gravel.

The distance between the top of the glacier threshold to the bottom of the depression is more than $10 \mathrm{~m}$ (Fig. 4). Zhang Xinpu (1960) and Xu Tieliang (1990) believed that the glacier threshold in the valleys of Nanhutashan Mountain and No. 2 valley of the Shesan Mountain is the result of landsliding. However, the lithology at the bedding in the glacier threshold and headwalls are identical and it is therefore unlikely that they originated from landslides. Similar glacier thresholds are distributed around the main peak district of Shesan Mountain.

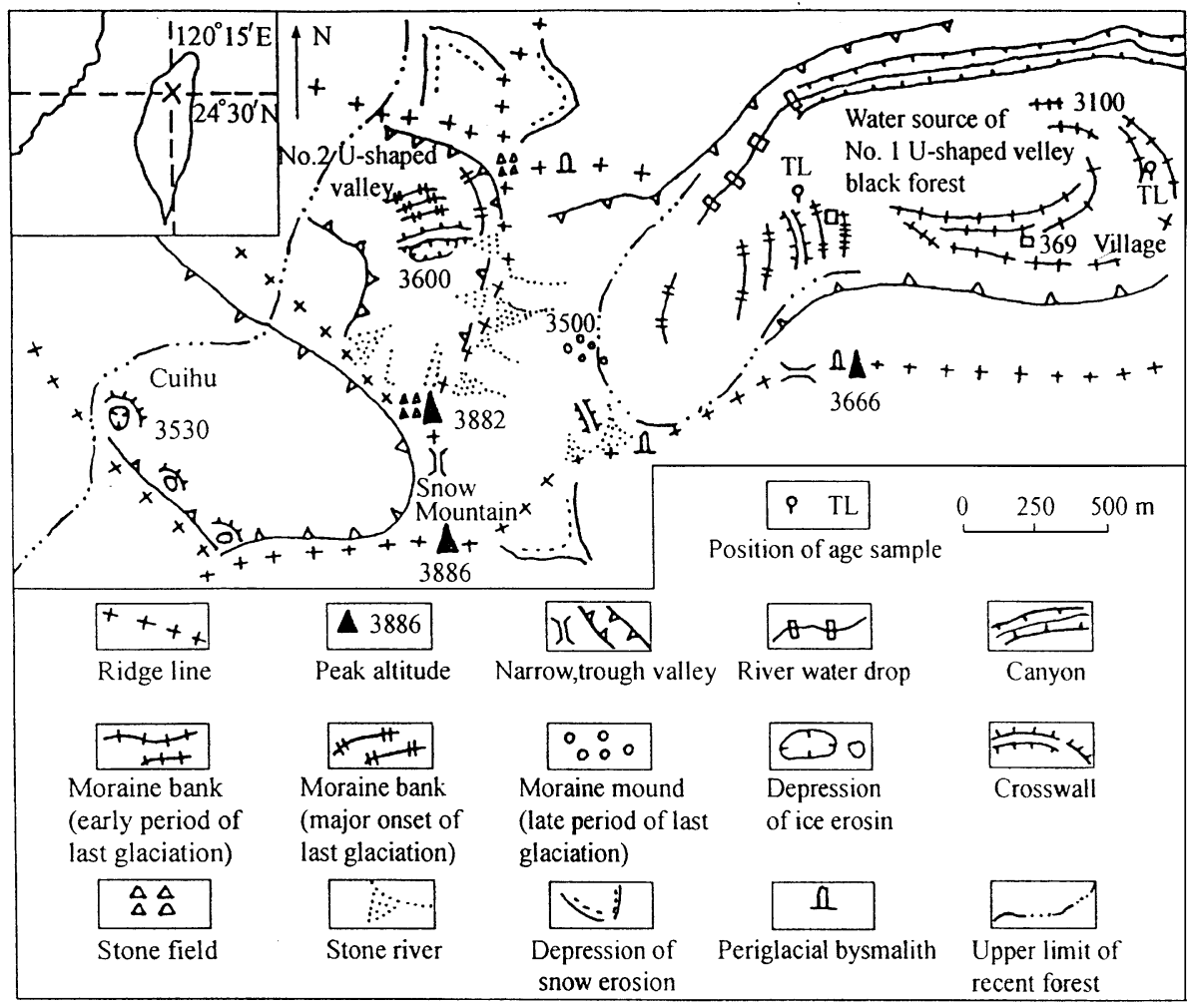

Fig. 1. The distribution of glacial landforms around the main peak of Shesan Mountain. 


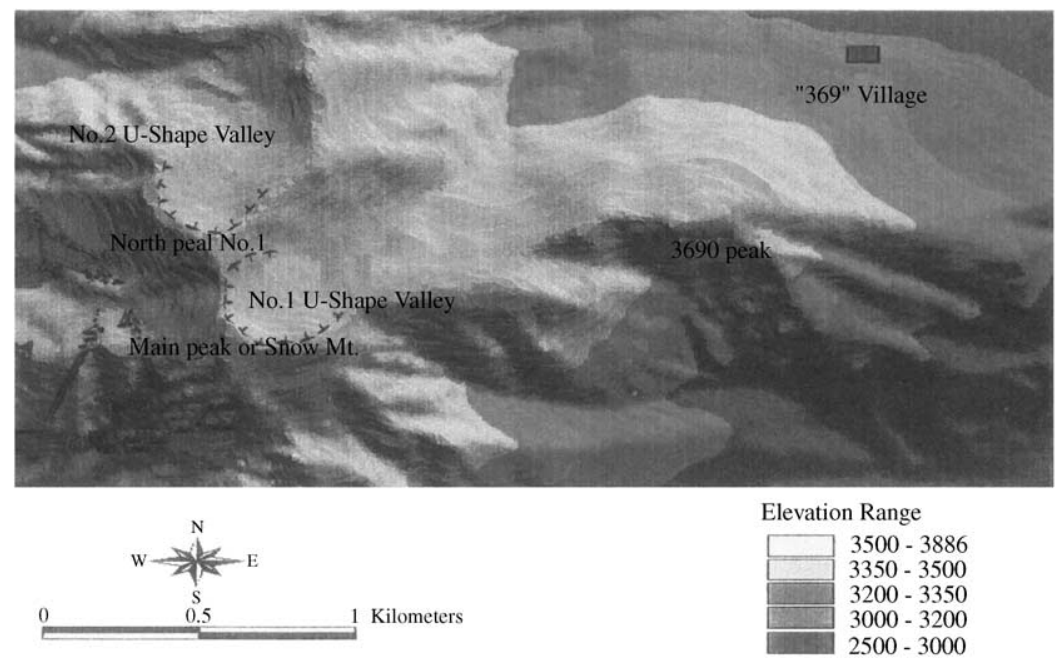

Fig. 2. DEM Image of valley of Shesan Mt.

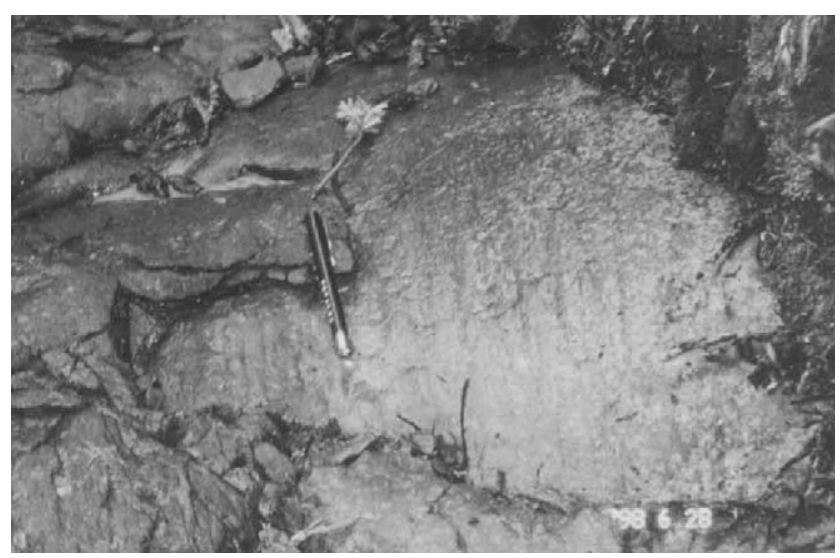

Fig. 3. Polished surface and striations of No. 1 valley of Shesan Mountain $(3400 \mathrm{~m})$ (photographed by Cui Zhijiu).

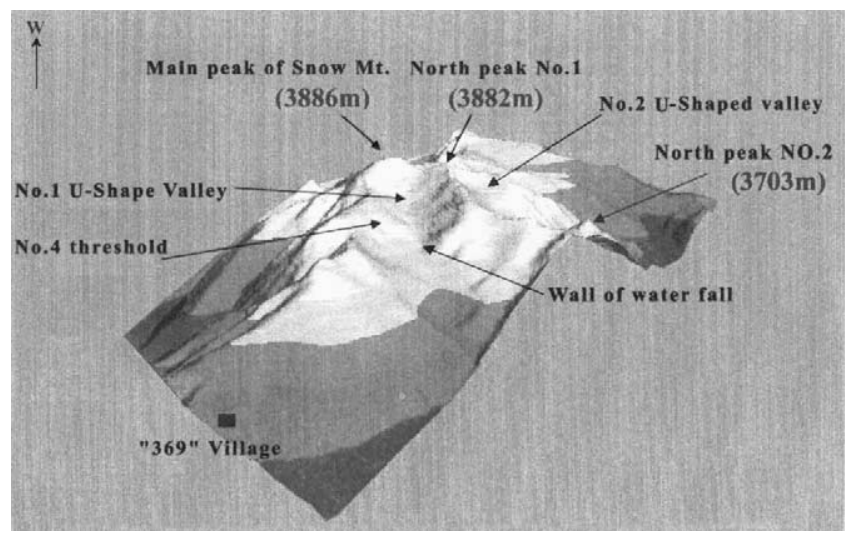

Fig. 4. DEM stereoscopic perspective image of Nos. 1 and 2 valleys of Shesan Mt.

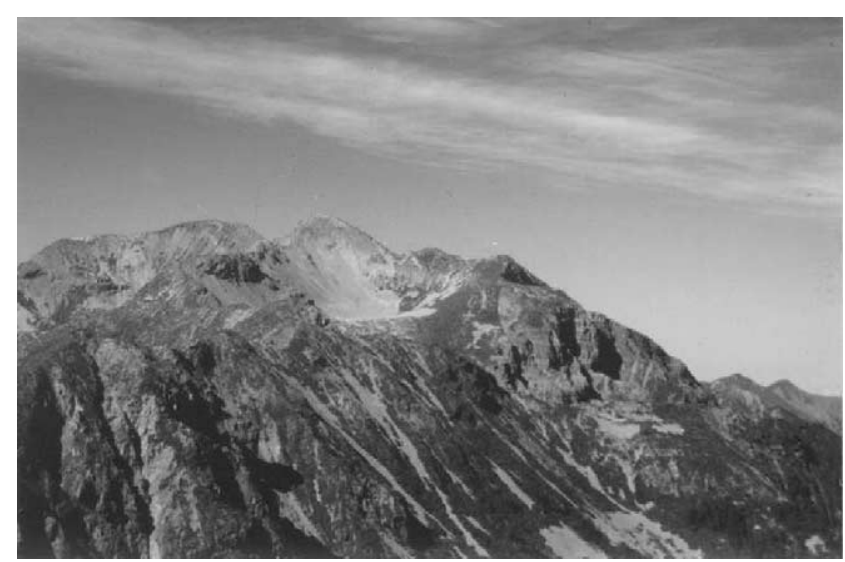

Fig. 5. Typical combination of cirques and glacier threshold in the No. 2 valley (photographed by Yang Jianfu).

\subsection{Moraines}

There are several moraines on the cirque floor and the glacier threshold of the No. 2 valley. There is also a lateral moraine on the eastern side of this valley. The moraines can be divided into three groups (lower, upper and uppermost) on the basis of their altitude and morphostratigraphy in No. 1 valley (Fig. 6).

\subsubsection{Lower moraines}

The lower moraines are located close to the " 369 " mountain refuge (Figs. 1 and 7). These $2 \mathrm{~km}$-long moraines extend $1 \mathrm{~km}$ lower than " 369 " mountain refuge from 3000 to $3400 \mathrm{~m}$ a.s.l. All moraines are confined to the southern side of No. 1 valley. The northern side of " 369 " refuge contains a canyon that is believed to have been a meltwater outlet. After the last 


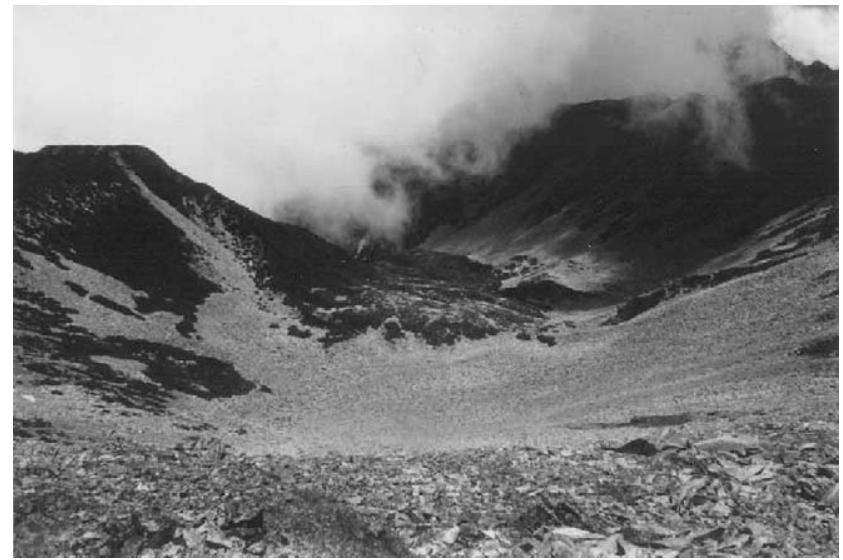

Fig. 6. Ice erosion basin and crosswall $(3600 \mathrm{~m}$ ) (photographed by Cui Zhijiu).

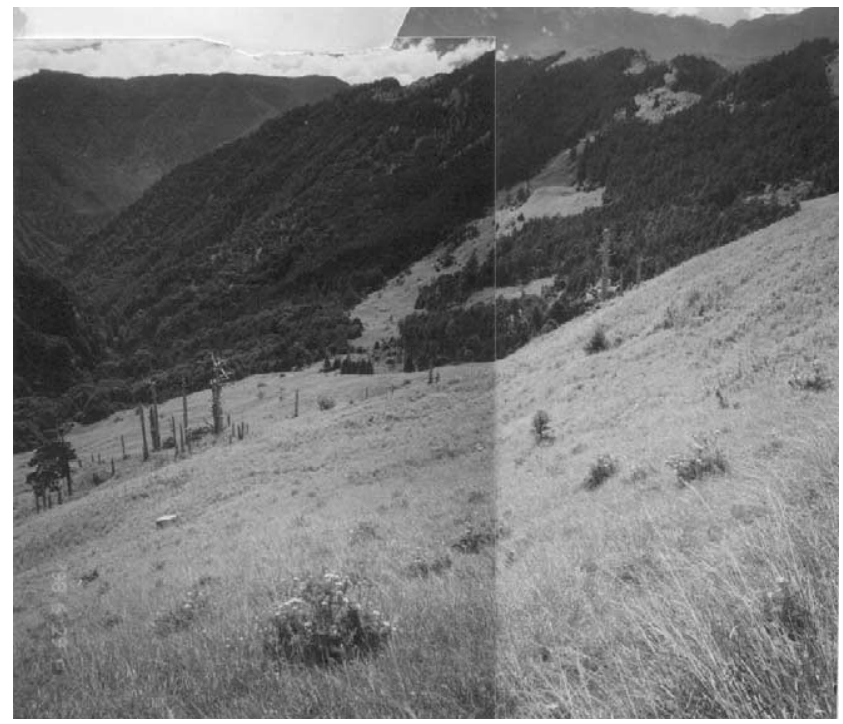

Fig. 7. The glacial moraine at the " 369 " mountain refuge $3200 \mathrm{~m}$ a.s.l. (photographed by Cui Zhijiu).

glaciation, streams dissected the cirque floor to form a canyon. The hill close to the "369" refuge displays an elongated form along the valley. It is comprised of sandstone, slate, quartzite and quartz veins. It is deeply weathered to red-yellow. The highland surface beneath a meadow is subdued. In the high mountains of the mainland, these subdued moraines were believed to be earlier than the last glaciation, because the surface of the moraine in the last glaciation has only a few boulders due to weathering. However, the earlier moraine surface has abundant boulders. A sample from the "369" mountain refuge section (Fig. 8) was used to do the TL dating by Chinese Academy Science Earthquake Institute. The section was located in a depression which is $500 \mathrm{~m}$ away from northern " 369 " mountain refuge, $100 \mathrm{~cm}$ long, $50 \mathrm{~cm}$ wide and $80 \mathrm{~cm}$ deep. The OSL age is $44.25 \pm 3.72 \mathrm{ka}$ (Table 1), corresponding to the earlier stage of the last glaciation (Tsukada, 1967; Li, 1992;
Ono and Naruse, 1997; Wang Xin, 1997; Tseng and Liew, 1998). We tentatively call this stage "Shangzhuang Glacial Stage". At that time, the length of glacier was about $4 \mathrm{~km}$ and the snow line was $3400 \mathrm{~m}$ a.s.l.

\subsubsection{Upper moraines}

Moraine ridges exist close to the water reservoir in the "Black Forest". The lower limit of their distribution is $3300 \mathrm{~m}$ a.s.l. The system comprises $4-5$ moraine ridges that reach the tree line about $3500 \mathrm{~m}$ a.s.l., including the above-mentioned glacier threshold and polished surface about $3400 \mathrm{~m}$ a.s.l. The end moraines are about $15 \mathrm{~m}$ in height and 100-150 $\mathrm{m}$ long. All of them are concentrated on the southern side of the valley, because the northern slope is steep. The southern slope is subdued and the river bed and canyon are located on the northern side. Therefore, the moraine ridges on the southern side are well preserved. This suggests that the southern side of the glacier melted faster. These upper moraines are sharp crested and have abundant boulders on their surfaces.

In addition, three terminal moraine banks are present outside the cirque basin and glacier threshold of No. 2 valley. These correspond to lateral moraine ridges of the same period. According to the altitude and their characteristics, the upper moraines seem to correspond to the onset of the last glaciation. Samples for TL dating were taken from the "Black forest" section (Fig. 9), located $1500 \mathrm{~m}$ from the main peak of Shesan Mountain. The section is $130 \mathrm{~cm}$ long, $80 \mathrm{~cm}$ wide and $80 \mathrm{~cm}$ deep. The ages of the lower and upper parts of the sediment in the "Black Forest" section are, respectively, $18.26 \pm 1.52$ and $14.28 \pm 1.13 \mathrm{ka}$ (Table 1), and the average age is $16.27 \pm 1.19 \mathrm{ka}$. This phase is tentatively termed the "Shuiyuan Glacial Stage". During this glaciation, the glacier was about $3 \mathrm{~km}$ long with an ELA at $\sim 3500 \mathrm{~m}$ a.s.1., which is now the same altitude as the upper limit of the forest.

\subsubsection{Uppermost moraines}

Small lateral moraines are present above the tree line ( $3500 \mathrm{~m}$ a.s.1.) in the No.1 valley at $3700 \mathrm{~m}$ a.s.l. on the northern steep slope of the main peak of Shesan Mountain. There are two lateral moraines composed of large boulders from above $3700 \mathrm{~m}$ a.s.l. on the northern side to the center of the valley, $250 \mathrm{~m}$ long and $3 \mathrm{~m}$ high. There is also a short lateral moraine on the southern side of the valley. These are in the bottom of valley, distributed below the glacier threshold of the Shuyuan Glacial Stage, and they probably formed later than the Shuiyuan Glacial Stage. On the basis of their form and distribution, we believe that they formed during the late period of the last glaciation. We assign these features to the "Xueshan Glacial Stage". At that time, the glacier was about $1.5 \mathrm{~km}$ long and the ELA was about $3700 \mathrm{~m}$ a.s.l. (Table 2). 


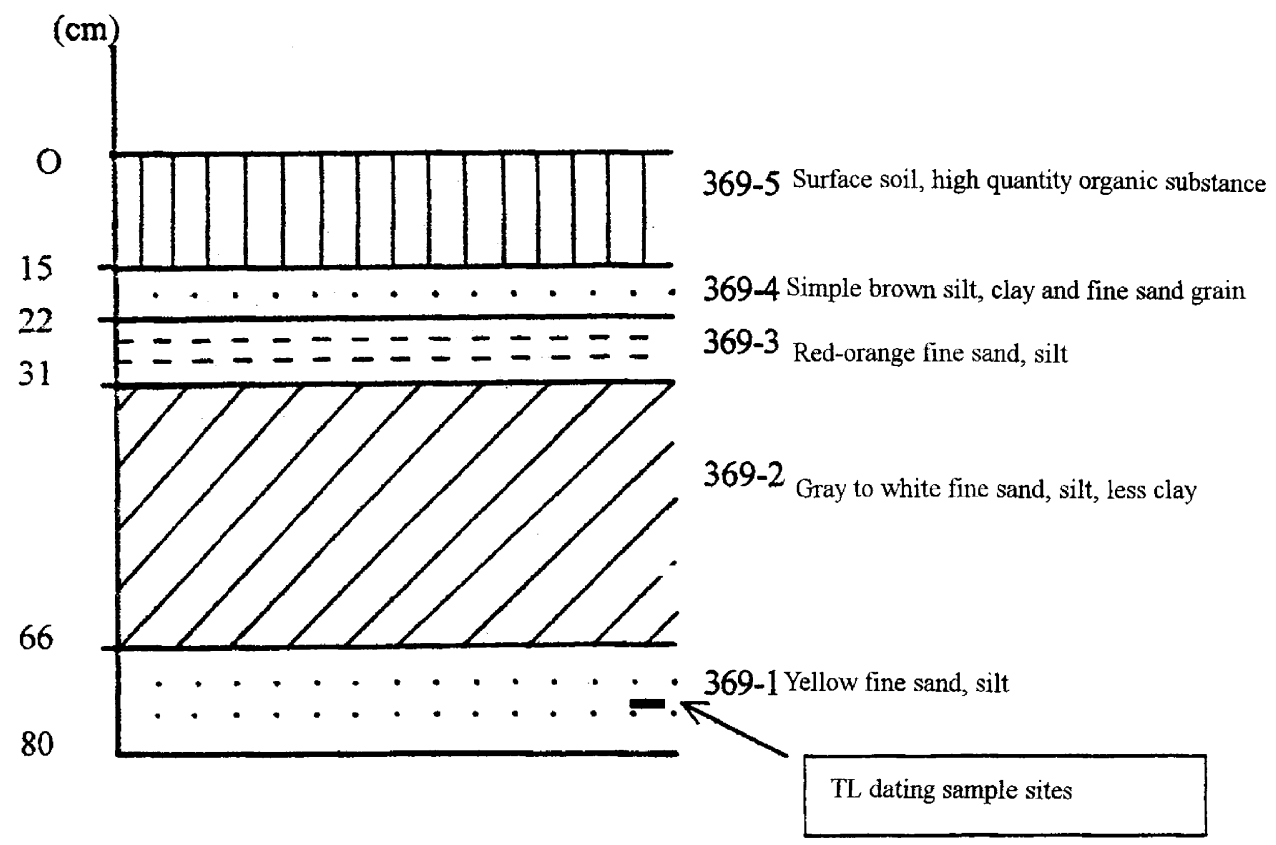

Fig. 8. Stratigraphy of "369" mountain refuge section.

Table 1

TL dating results for sediments in "Black Forest" and "369" mountain refuge sections

\begin{tabular}{lllcll}
\hline Sample location & Sample number & Soil depth $(\mathrm{cm})$ & Equivalent dose $(\mathrm{Gy})$ & Dose rate $(\mathrm{Gy} / \mathrm{a})$ & Age $(\mathrm{ka})$ \\
\hline Lower "Black Forest" section & SSH-1 & 80 & 72.50 & 0.00397 & $18.26 \pm 1.52$ \\
Middle "Black Forest" section & SSH-3 & 55 & 67.97 & 0.00476 & $14.28 \pm 1.13$ \\
Upper "Black Forest" section & SSH-4 & 30 & 54.34 & 0.00509 & $10.68 \pm 0.84$ \\
"369" mountain refuge section & $369-1$ & 70 & 138.95 & 0.00314 & $44.25 \pm 3.72$ \\
\hline
\end{tabular}

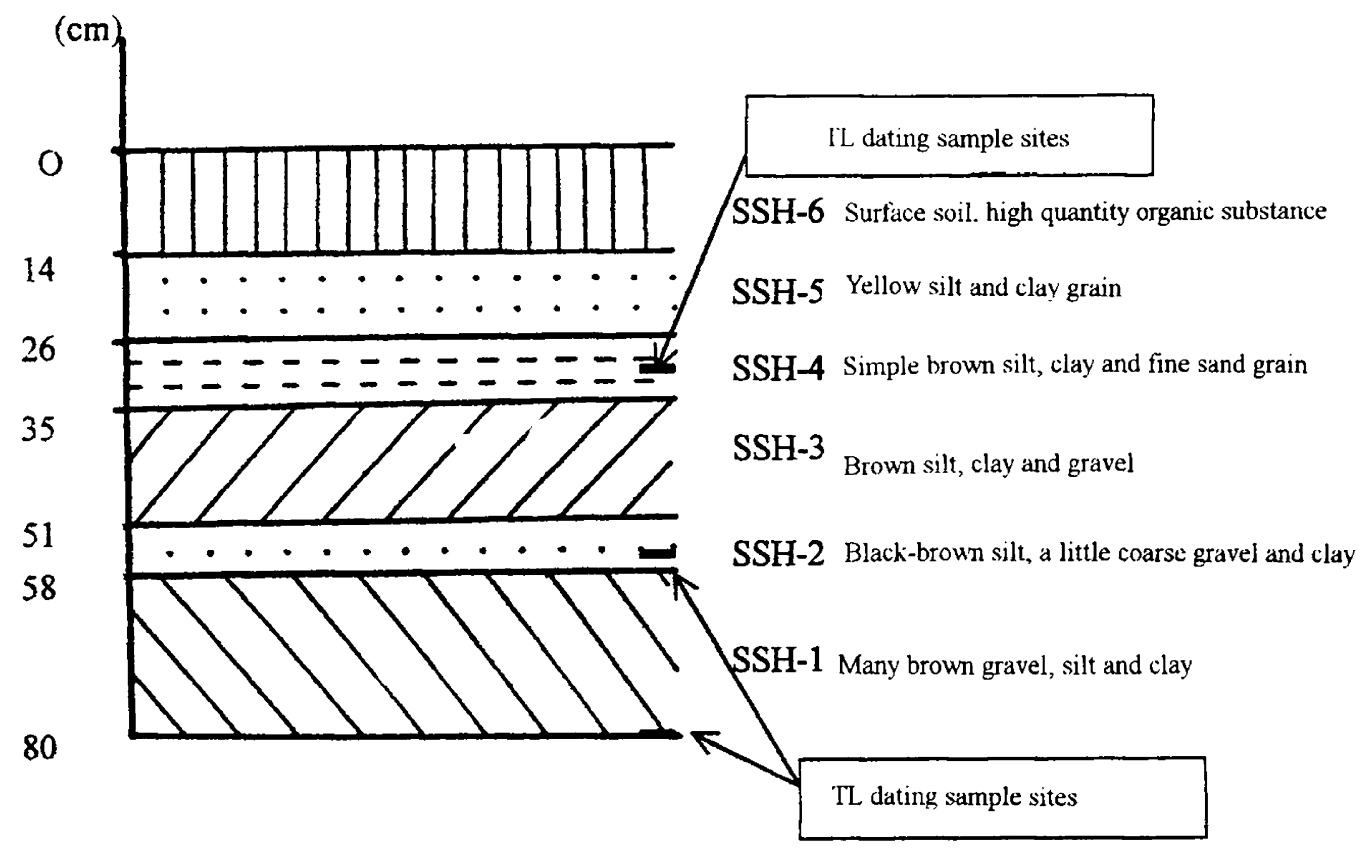

Fig. 9. Stratigraphy of "Black Forest" section. 
Table 2

Glacial chronology for the Shesan Mountain of Taiwan

\begin{tabular}{|c|c|c|c|c|c|c|}
\hline Ice age & Glacial stage & $\begin{array}{l}\text { Snowline } \\
\text { elevation }(\mathrm{m})\end{array}$ & $\begin{array}{l}\text { Glacial } \\
\text { tongue (m) }\end{array}$ & $\begin{array}{l}\text { Glacial } \\
\text { type }\end{array}$ & $\begin{array}{l}\text { Glacial } \\
\text { length }(\mathrm{km})\end{array}$ & TL age (ka) \\
\hline \multirow{3}{*}{$\begin{array}{l}\text { Last } \\
\text { Glacial }\end{array}$} & Xueshan & 3700 & 3500 & Cirque & 1.5 & $\begin{array}{l}10.68 \pm 0.84 \\
18.26 \pm 1.52 \text { (lower) }\end{array}$ \\
\hline & Shuiyuan & 3500 & 3300 & Cirque valley & 3 & $14.28 \pm 1.13$ (upper) \\
\hline & Shanzhuang & 3400 & 3100 & Valley & 4.5 & $44.25 \pm 3.72$ \\
\hline
\end{tabular}

\section{Discussion}

Table 2 shows the existence of early and late glacial stages in the last glaciation in Taiwan, which is similar to the glacier fluctuation recorded in the Japanese high mountains (Ono and Naruse, 1997), but contrasts with the glacial record in mainland China (Zhang Xinpu, 1960; Li, 1992). On the western, southern and eastern edges of the Tibetan Plateau, some mountains such as Everest, Nyaingentanglha, Karakorum, Diancangshan in Yunnan, and the eastern part of Qilian Shan, which are in monsoonal areas, have glacial landforms that formed during the earlier part of the last glacial. However, these remains are absent in the arid areas of Central Tibet. This difference suggests that there were different types of monsoon area. Seasonal differences and differences of geographic location caused the distinctness of the conditions of precipitation and temperature. In some areas, such as along the Pacific shore, there is abundant precipitation in winter. The other type of monsoon area receives some precipitation in summer in the interior of the mainland. The climates of the Pacific monsoonal areas were instrumental in the accumulation of glaciers, which made the early and late period of the last glaciation obvious in the high mountains of Taiwan and Japan. They were relatively sensitive to climate changes. The scale of glaciation during the early period of the last glaciation was the largest. $\mathrm{Li}$ (1992) estimated that the precipitation of the early period of Last Glacial Maximum (20 ka) was onethird more than that during the onset of the major phase of glaciation.

Based on research (Li, 1992; Ye Baishen et al., 1997) of the glacial development during the last glaciation, we found that the precipitation along the west shore of the Pacific at that time was $15-30 \%$ lower than at present. Precipitation did not have a profound influence on the high mountains of Taiwan, because here precipitation was up to $3000-4000 \mathrm{~mm}$ per year and the glacial development was of the oceanic type. Pollen analysis (Tseng and Liew, 1998; Tsukada, 1967; Wang Xin, 1997) suggests that there was a cold and dry period in the early part of the Last Glacial Maximum. Gelsemium tortoise, which requires a cold climate, had formerly lived in the high mountain areas, and could represent indirect evidence of glaciation of Shesan Mountain. Presently they live in Qijiawan Brook of Xueshan, and have adapted to the cool temperature of the high mountain environment. This shows the southern boundary of the distribution of this organism in Asia. This biological evidence supports the existence of glaciation of the main peak of Shesan Mountain of the last glaciation, and also could explain former existence of G. tortoise. The No. 1 valley is the source of Qijiawan Brook, so the glacier of No. 1 valley should have disappeared in the latest stage of the last glaciation. This would be in conformity with the conditions of the glacial development, if the average annual temperature at the snow line were kept between $-1{ }^{\circ} \mathrm{C}$ and $-3^{\circ} \mathrm{C}$. The biological evidence suggests that the temperature was $5^{\circ} \mathrm{C}$ lower than at present.

The ELA of northern slope of the main peaks of the Xueshan Mountain was about $3600 \mathrm{~m}$ a.s.l. If we considered the altitude of the bottom of the cirque as representative of the ELA (we did not consider the uplift of the mountain or changes in sea level) then the former ELA for the northeastern face was about $3500 \mathrm{~m}$ a.s.1. This is a little lower than that of the northern face. This suggests that the northeastern direction faced into the wet air stream, favoring snow accumulation.

\section{Conclusion}

Based on the development characteristics of the last glaciation in Taiwan, combined with the known information from mainland China, Japan and Siberia, we found that glacier development was not favored by the winter monsoon that was strengthened over Asia during the MIS 2 and MIS 4. The climate was dry and cold, and rainfall decreased by about one-third $(\mathrm{Li}$, 1992). Especially, dry winter climate marked MIS 2. However, glaciers were well developed along a line between East Siberia through Japan (Ono, 1988, 1991) and Taiwan because the monsoon rain supported these regions during the winter, which aided glacier 
development. Furthermore, the glaciers during the earlier last glaciation $(40-50 \mathrm{ka})$ were greater than those in the late glaciation $(10-11 \mathrm{ka})$, and also greater than those during the maximum glaciation (15-18 ka). This is an important feature of mountain glacier development in maritime East Asia. This tendency, however, weakened gradually as glaciers advanced into the inland areas from east to west. It also has some consequences from the Yulong Shesan Mountain to the south, Qilian Shan to the north, and Lenglongling to the east $(\mathrm{Li}$, 1992), while further inland the effects were not as clear. In summary, the winter monsoon became stronger, the wind, sand, loess, and ice fringes expanded, but the glaciers suffered due to scarcity of precipitation.

\section{Acknowledgements}

The authors are grateful to Academician Shi Yafeng, and Professors Lewis Owen and Yuko Ono for their help in preparing the manuscript. This work was supported by the National Natural Science Foundation of China (No. 49671010).

\section{References}

Bose, M., 1997. Geomorphologic evidence of late Pleistocene glaciation in the high mountains of Taiwan. Proceedings of the Fourth International Conference on Geomorphology, Bologna, p. 91.

Ceng Chaoxian, 1993. Physical Geography of Taiwan. Map Press, Guangdong, pp. 24-28.

Cui, Z.J., Yang, J.F., Liu, G.N., Song, G.C., Wang, X., 2000a. Monsoon development and glacier disappearance-from the point of view of glacier revolution during last glaciation in Xueshan, Taiwan. Journal of Glaciology and Geocryology 22, 7-13 (in Chinese with English abstract).

Cui, Z.J., Yang, J.F., Liu, G.N., Song, G.C., Wang, X., 2000 b. Discovery of Quaternary glacial evidence on Shesan Mountain in Taiwan, China. Chinese Science Bulletin 45, 566-571.

Kano, T., 1932. Some topographical observations about the mountain land of Formosa. The Geographical Review of Japan, 8, 196-202; 505-520.
Kano, T., 1934a. First contribution to the study of glacial topography of Tugitaka Mountains, Formosa (1). The Geographical Review of Japan 10, 606-623.

Kano, T., 1934b. First contribution to the study of glacial topography of Tugitaka Mountains, Formosa (2). The Geographical Review of Japan 10, 688-707.

Kano, T., 1934c. First contribution to the study of glacial topography of Tugitaka Mountains, Formosa (3). The Geographical Review of Japan 10, 816-835.

Kano, T., 1934d. First contribution to the study of glacial topography of Tugitaka Mountains, Formosa (4). The Geographical Review of Japan 10, 990-1017.

Kano, T., 1934e. First contribution to the study of glacial topography of Tugitaka Mountains, Formosa (5). The Geographical Review of Japan 11, 244-263.

Li, J., 1992. The ancient glacial remains of season Asia of last glaciation. Quaternary Research, 332 (in Chinese).

Lin, C., 1957. Geomorphology, Taipei. The Reference Committee of Taiwan, Beijing 1, 424.

Ono, Y., 1988. Last glacial snowline altitude and paleoclimate of East Asia. Daiyonki-Kenkyu 26, 271-280.

Ono, Y., 1991. Glacial and periglacial paleoenvironments in the Japanese Islands. Daiyonki-Kenkyu 30, 203-211.

Ono, Y., Naruse, T., 1997. Snowline elevation and eolian dust flux in the Japanese islands during isotope stages 2 and 4. Quaternary International $37,45-54$.

Tanaka, K., Kano, T., 1934. On the glacial landforms in Mt. Nanhutashan, Taiwan. Geographical Review 10, 169-190.

Tseng, M.H., Liew, P.M., 1998. Digital relationship of the surface and fossil pollen by correspondence analysis. Proceedings of the Seventh Symposium on Taiwan Quaternary, pp. 18-23. (in Chinese with English abstract).

Tsukada, M., 1967. Vegetation in subtropical Formosa during the Pleistocene glaciations and the Holocene. Palaeoclimatology, Palaeogeography, Palaeoecology 3, 49-64.

Wang Xin (1997). Geological action of glacial river period based on the ancient plant and climate. Proceedings of the Plant Resources of Taiwan. Taipei, Taiwan University, pp. 229-238.

$\mathrm{Xu}, \mathrm{T} .$, 1990. Discussion of glacial landform of Nanhutashan Mountain. Geology 10, 79 (in Chinese).

Yang, C.F., Cui, Z.J., Wang, S., Song, Q.C., 1998. Relics of the Last Glacial Maximum in Shesan Area. Proceedings of the Seventh Symposium on Taiwan Quaternary, pp. 8-12 (in Chinese with English abstract).

Ye, B.S., Li, S.J., Shi, Y.F., 1997. Investigation of climatic conditions by the glacier extension in the Last Glacial Maximum. Journal of Glaciology and Geocryology 19, 1-9 (in Chinese with English abstract).

Zhang, X., 1960. Discussion of the ice erosion landforms of Nahudashan Mountain. Journal of Chinese Geological Society, 109. 